\title{
Planetary Regolith Delivery Systems for ISRU
}

\author{
James G. Mantovani ${ }^{1}$, and Ivan I. Townsend $\mathrm{III}^{2}$ \\ Surface Systems Office, NE-S-1, NASA Kennedy Space Center, Florida 32899; \\ $\mathrm{Ph}$ (321) 867-1870; email: james.g.mantovani@nasa.gov \\ ${ }^{2}$ AGT-ESC, ESC 48, Kennedy Space Center, Florida 32899; Ph (321) 867-9442; \\ email: ivan.i.townsend@nasa.gov
}

\begin{abstract}
The challenges associated with collecting regolith on a planetary surface and delivering it to an in-situ resource utilization system differ significantly from similar activities conducted on Earth. Since system maintenance on a planetary body can be difficult or impossible to do, high reliability and service life are expected of a regolith delivery system. Mission costs impose upper limits on power and mass. The regolith delivery system must provide a leak-tight interface between the near-vacuum planetary surface and the pressurized ISRU system. Regolith delivery in amounts ranging from a few grams to tens of kilograms may be required. Finally, the spent regolith must be removed from the ISRU chamber and returned to the planetary environment via dust tolerant valves capable of operating and sealing over a large temperature range. This paper will describe pneumatic and auger regolith transfer systems that have already been field tested for ISRU, and discuss other systems that await future field testing.
\end{abstract}

\section{INTRODUCTION}

The regolith found on the Moon, Mars and even on asteroids is composed of minerals containing metals and various oxides that are recognized to be potential resources that can be mined and processed chemically to extract useful by-products, such as oxygen, water, metals and metal alloys. One goal of in-situ resource utilization (ISRU) is to produce substances like oxygen that are expected to be consumed during extended human explorations on planetary surfaces. An in-situ capability to generate missioncritical consumables, such as water and oxygen, will help extend the duration of a mission, increase its productivity, and reduce the overall cost of the mission by either eliminating or significantly reducing the need to transport those materials from Earth.

Surface system operations involving the excavation and transport of regolith (e.g., by rovers with blades and buckets, drill corers, lander scoops) are among the possible activities that will be conducted on planetary bodies to provide feedstock material to an ISRU system (e.g., chemical reactor, chemical analyzer). A planetary base might even utilize the sintered "waste" material produced during ISRU chemical processing to construct habitats and landing pads, and to provide radiation protection from the Sun. NASA seeks technology advancements in the areas of regolith conveying in order to achieve the goals and objectives of present and future ISRU activities. These systems must be efficient and provide reliable performance over long durations of 
time while exposed to harsh environments found on planetary surfaces. Those surface conditions will include contact with very abrasive regolith particulates, reduced gravity, wide variations in temperature, exposure to either high vacuum or a partial atmosphere, and exposure to solar and space radiation.

Project requirements provide challenges to delivering regolith to an ISRU system on a planetary surface as compared to conducting similar activities on Earth. Mission cost considerations drive the system design towards minimizing the overall power consumption and total mass while maintaining high mechanical efficiency and reliability. The regolith delivery system must also interface between the near-vacuum environment on a planetary surface and the closed atmosphere inside an ISRU system where the temperature and pressure must be precisely controlled. Regolith feedstock in amounts ranging from a few grams to tens of kilograms may need to be delivered to specific locations in the ISRU system where chemical reactions, processing and analyses occur. Eventually, the spent regolith must be removed from the ISRU chamber and returned to the planetary environment by means of dust tolerant valves that must be capable of operating over a wide temperature range.

Regolith conveying techniques that combine a reduction in failure modes and low energy consumption with increases in material transfer rates will provide significant value for future space exploration missions to the surfaces of the moon, Mars and asteroids. Experimental testing and modeling efforts in support of NASA's ISRU project have been conducted at NASA Kennedy Space Center to advance the technological readiness level of pneumatic regolith delivery and mechanical auger systems. These techniques have been shown in recent years to be viable regolith delivery systems as a result of field testing under terrestrial and reduced gravity conditions.

The NASA ISRU project is concerned with extracting oxygen from minerals like ilmenite in lunar regolith through chemical processes that take place in a fluidizedbed reactor system (Mueller 2010). The ISRU regolith transfer team identified the flow and transfer characteristics of lunar regolith simulants to be a concern for oxygen production efforts. It is important to develop a hardware design that allows a given amount of lunar regolith simulant to flow and be transferred to a desired vertical height under lunar gravity conditions. The first generation of the hydrogen reduction ISRU project (ROxygen I) tested an inclined auger regolith feed system to transfer material vertically $7 \mathrm{ft}$ above the ground and into a solids inlet located at the top of an ISRU reactor chamber. For ROxygen II, a pneumatic method was designed to convey the regolith vertically and avoided exposing moving parts to abrasive regolith simulant particles. Pneumatically conveyed granular material is separated from the convey gas using cyclone separator technology. A "proof of concept" pneumatic regolith transfer system was built for the Carbothermal ISRU project and field tested at Mauna Kea in 2010. Methane is utilized in the carbothermal reduction process to extract oxygen from heated metal oxide minerals.

This paper will discuss the pneumatic system that was field tested at Mauna Kea in February 2010, and an auger system that was field tested at Mauna Kea in Nov 2008. 
We will also discuss other regolith conveying techniques that have been investigated at NASA Kennedy Space Center and await future field testing.

\section{PNEUMATIC CONVEYING OF PLANETARY REGOLITH}

Pneumatic conveyor systems are commonly used by the chemical and mineral industries to transfer dry, bulk granular materials along a pipeline on Earth. A source of compressed gas provides the energy needed to convey the material at a desired mass flow rate. The advantage that pneumatic conveyors have over other methods of delivering planetary regolith into ISRU systems is that they do not have any moving parts to expose to abrasive mineral particulates during the regolith transfer process. A high level of friction between dust covered sliding or contacting surfaces like gears can cause moving parts to clog up and eventually fail. While it may not be practical to deploy a pneumatic regolith delivery system as a "standalone" system on a planetary surface mission, it becomes viable when an ISRU system already has a requirement for gas handling since a gas compressor and possibly a storage tank would be available. Gas handling is needed in an oxygen producing ISRU chemical reactor in which water vapor is produced during a chemical reaction between gas and regolith heated to high temperatures. A supply of hydrogen gas is needed in the hydrogen reduction of ilmenite, and methane is used in the carbothermal reduction of silicates and titanates. Those chemical reactions produce a desired by-product that is either collected for direct use, such as water vapor, or else is converted into another substance, e.g., by electrolyzing the collected water to produce gaseous oxygen.

Figure 1 illustrates a pneumatic regolith delivery system that was developed at NASA Kennedy Space Center to study pneumatic conveying of lunar regolith simulants such as JSC-1A, NU-LHT and Tephra using air and helium as convey gases for reduced gravity flight experiments at $1 / 6-\mathrm{g}$. The same experimental setup could also be used for ground testing at 1-g. Regolith was pneumatically conveyed as a dense phase flow of dusty gas along a pipeline from an eductor attached to the base of the supply cylinder up to a receiving cylinder that served as an ISRU reactor mockup. A double cyclone array shown in Fig. 1(d) includes a primary cyclone that deposits most of the regolith into a receiving cylinder, and a smaller secondary cyclone that filters the exhaust gas from the primary cyclone before venting the gas through a primary HEPA filter into the secondary containment box. A secondary HEPA filter is mounted at the top of the secondary containment box to prevent the box from becoming pressurized and to allow doubly filtered air to safely enter the aircraft cabin. The exterior of the secondary containment box provides access to gas pressure regulators that allow for manual control of the input gas pressures applied to the supply cylinder for fluidizing the regolith, and to the eductor for conveying regolith. The interface panel includes gauges to monitor gas pressures and the input gas flow rate from compressed gas cylinders. There also is access to the regolith solids valve. The secondary containment box has an aluminum frame and aluminum supports with polycarbonate sheets that must be able to withstand the maximum g-loads that the system could experience during takeoff and landing of the reduced gravity flight. 

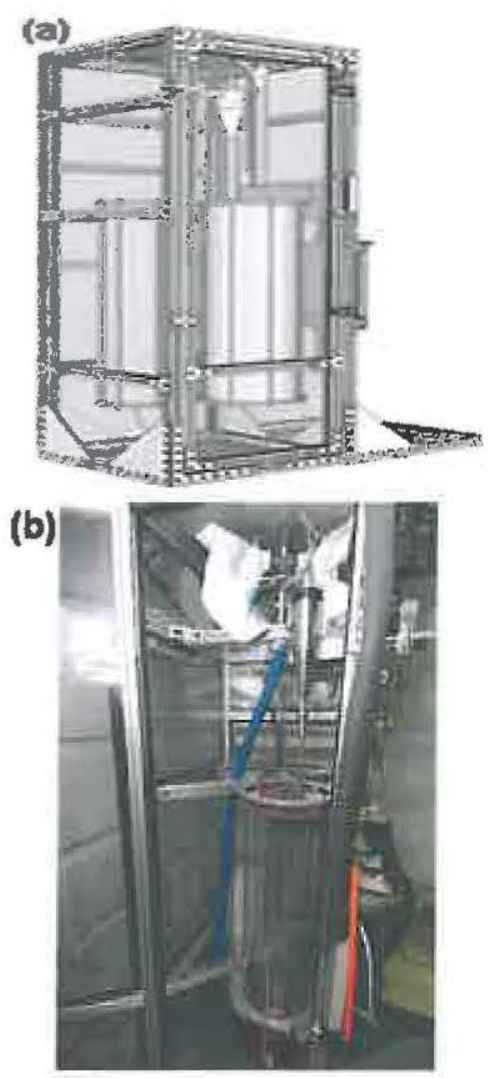

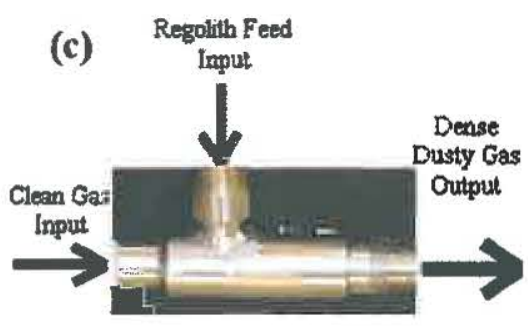

(d)

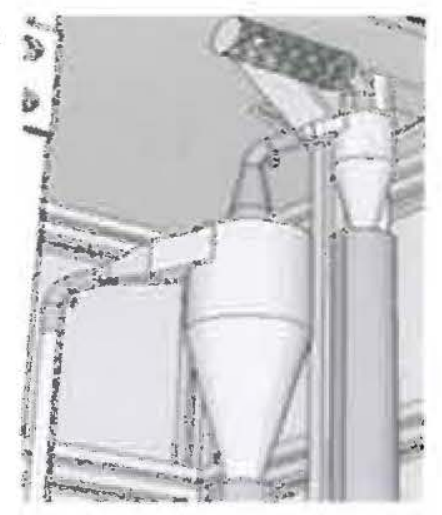

Figure 1. (a)Schematic and (b) photo of hardware used to study pneumatic conveying of regolith simulant as a reduced gravity flight experiment under lunar gravity $(1 / 6-\mathrm{g})$ conditions. The total mass of the flight rig was $195 \mathrm{~kg}$ including $16.5 \mathrm{~kg}$ of lunar regolith simulant. (c) Venturi eductor creates a dusty gas flow by mixing fluidized regolith in a supply cylinder with a flow of pure gas. (d) A series array of mechanical cyclone separators was used to filter the particles transferred to a maximum height of $1.5 \mathrm{~m}$ by the convey gas into a receiving cylinder. See text for further details.

The goal of a regolith delivery system for ISRU applications is to deliver regolith to an ISRU system at the highest mass flow rate while using the least amount of power and minimizing the delivery system's mass. The amount of regolith that needed to be delivered was set at $16.5 \mathrm{~kg}$ based on the oxygen production rate that the ISRU reactor was expected to generate per batch of regolith. A high regolith mass flow rate requires a dense flow of dusty gas through the pipeline and results in a demand for highly efficient mechanical cyclone separators. The particles that are able to be conveyed pneumatically vary in size from a fine powder to several millimeters in diameter or greater depending on the particle density and the pipe's inner diameter. Although the composition of the granular material is mineral, friable particulates are vulnerable to breakage by collisions with walls at the bends located along the pipeline.

The eductor (see Fig. 1(c)) is a device that produces a dense-phase gas-solids mixture that flows along a pipeline. When pure gas flows through a nozzle located inside the eductor, the venturi effect produces a low pressure region at the nozzle that facilitates 
movement of solids into the gas flow. The solids enter the flow from a supply bin that is maintained at a slightly greater relative gas pressure than that at the nozzle by fluidization. The gas-solids mixture is then pneumatically conveyed to a receiving bin where the solids are separated from the gas using mechanical cyclone separators and then deposited into the receiver. The gas-solids mixture is pneumatically conveyed in a manner that is influenced by (1) the granular particle size and shape distributions, (2) the gas temperature, pressure, flow rate, molecular mass, and (3) the shape, length and material properties of the pipeline. The pipeline shape may be straight, bent or curved, and it may have any number of horizontal and vertical sections.

"Open" pneumatic regolith transfer systems exhaust the convey gas into the ambient environment, as in Fig. 1, and use a fresh supply of compressed gas to continue the regolith transfer process. "Closed" pneumatic transfer systems recover the gas that is filtered at the receiver and return it to a compressor for repeated use. For example, Honeybee Robotics and NASA KSC developed the closed pneumatic regolith delivery system in Fig. 2 for the Carbothermal ISRU field test at Mauna Kea in 2010. The canister with the NASA logo contains a HEPA filter to remove very fine Tephra particles that were exhausted from the series array of two mechanical cyclones shown connected to the filter canister. The filtered air was returned for reuse to a compressor shown below the regolith supply hopper. Regolith was delivered to the Carbothermal reactor from the black chute shown below the primary cyclone. A smaller cyclone filtered the exhaust from the main cyclone and deposited particles into the same chute.

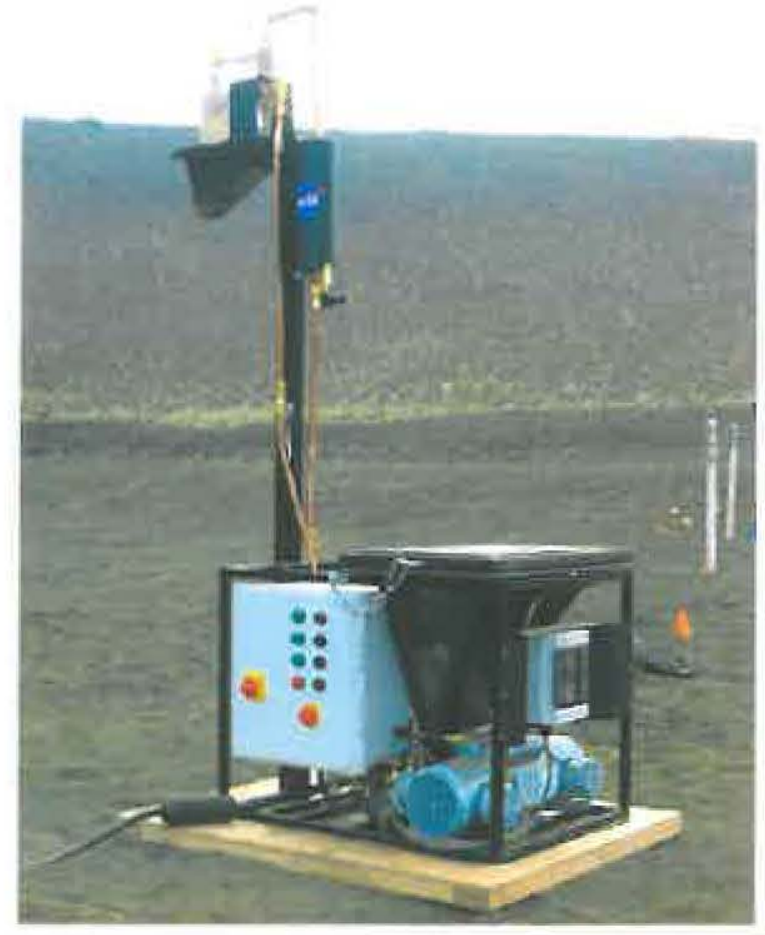

Figure 2. Automated closed-loop pneumatic regolith feed system developed for the Carbothermal reactor ISRU field test at Mauna Kea in 2010. 
Experiments were conducted at KSC to determine the mass flow rate of pneumatically conveyed JSC-1A lunar regolith simulant as a function of convey gas (air) flow rate and pressure. In Fig. 3, the cylindrical supply hopper connects to the eductor's solids inlet via a manual ball valve. An air supply line connects to the eductor's gas inlet. An independent air line connects to the supply hopper to fluidize the regolith. The outlet line of the eductor empties into the enclosure. The entire setup rests on a large digital mass scale to record the transient mass loss as regolith particles are transported as a dense-phase gas-solids flow along the eductor outlet line toward the open end.
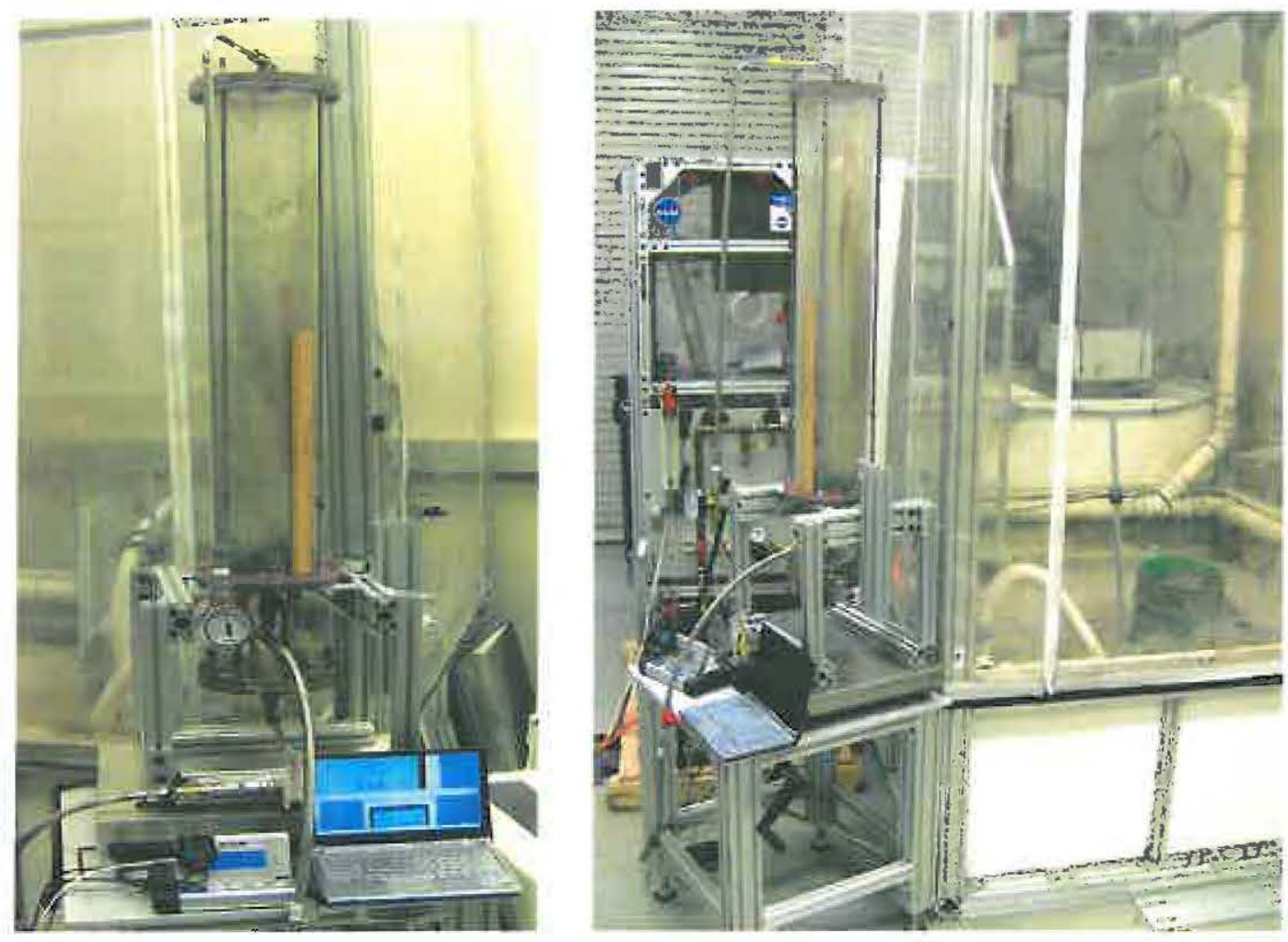

Figure 3. Experimental setup to determine the mass flow rate of JSC-1A using dry compressed air both as the convey gas and to fluidize the lunar regolith simulant contained in the acrylic supply cylinder show in the front view (left image) and side view (right image). The right image shows how granular material is educted at the bottom of the supply cylinder and flows freely along a horizontal pipe into an open bucket located inside an enclosure that keeps air borne particulates inside.

The results of experiments involving the pneumatic regolith feed system in Fig. 3 are presented in Figures 4-6. Compressed dry air was used to convey and to fluidize $\sim 5 \mathrm{~kg}$ batches of JSC-1A in 1-g gravity. Figure 4 shows graphs of the net mass of conveyed JSC-1A as a function of time for two cases of air pressures applied to the eductor gas inlet (left image: $1.3 \mathrm{psig}$, and right image: $5.4 \mathrm{psig}$ ), but with the same fluidization pressure inside the supply cylinder (10 psig). The left graph shows that after an initial delay, JSC-1A begins to flow from the supply cylinder and into the eductor. It is then conveyed along the horizontal pipeline and into the ambient environment. The right graph shows a briefer initial delay time, and a slightly lower mass flow rate. Both 
curves finally level off when nearly all regolith has been removed. The mass flow rate of regolith is determined by calculating the slope of the straight line section in each of these curves (left: $6.4 \mathrm{~kg} / \mathrm{min}$, right: $6.1 \mathrm{~kg} / \mathrm{min}$ ).
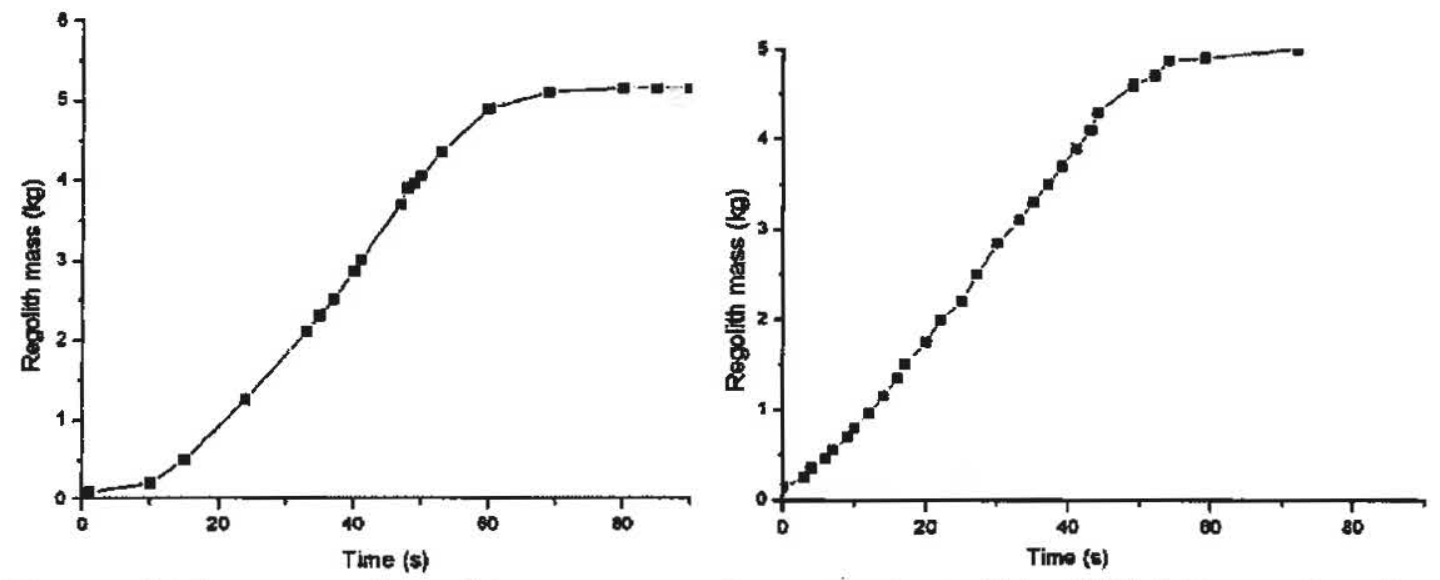

Figure 4. Two examples of the net mass of conveyed regolith (JSC-1A) as a function of time for given gas pressures applied to the supply cylinder for fluidizing the regolith and to the eductor gas inlet for conveying the regolith: (left) fluidization: 24.7 psia, eductor: 16 psia; (right) fluidization: 24.7 psia, eductor: 20.1 psia.

As indicated below in Fig. 5, the regolith mass flow rate actually decreases with increasing applied gas pressure at the eductor's gas inlet for fixed fluidization pressure in the supply cylinder, namely 5 psig (lower curve) and 10 psig (upper curve).

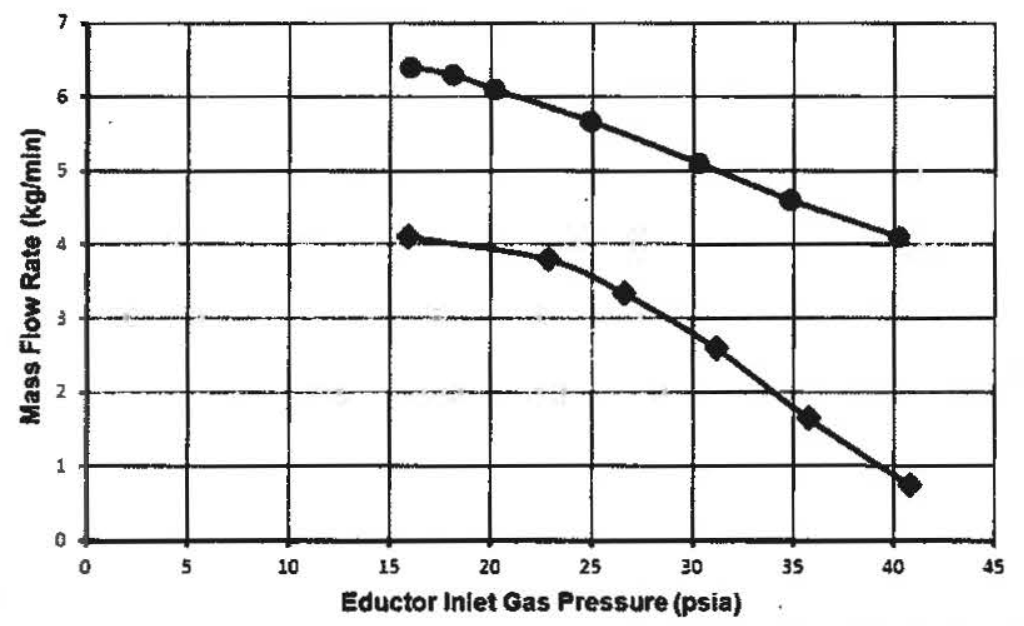

Figure 5. Mass flow rate versus eductor inlet gas pressure for conveying JSC-1A into ambient environment under 1-g using compressed dry air as the convey gas. Upper curve (solid circles) is for the supply cylinder fluidized at a pressure of 24.7 psia, while the lower curve (solid diamonds) is for a fluidization pressure of $19.7 \mathrm{psia}$.

As shown below in Fig. 6, the mass flow rate is also inversely related to the gas flow rate into the eductor for the same two fixed fluidization pressures in the regolith supply cylinder. It should be noted that the eductor inlet gas pressure is controlled but the eductor inlet gas flow rate can only be measured. 


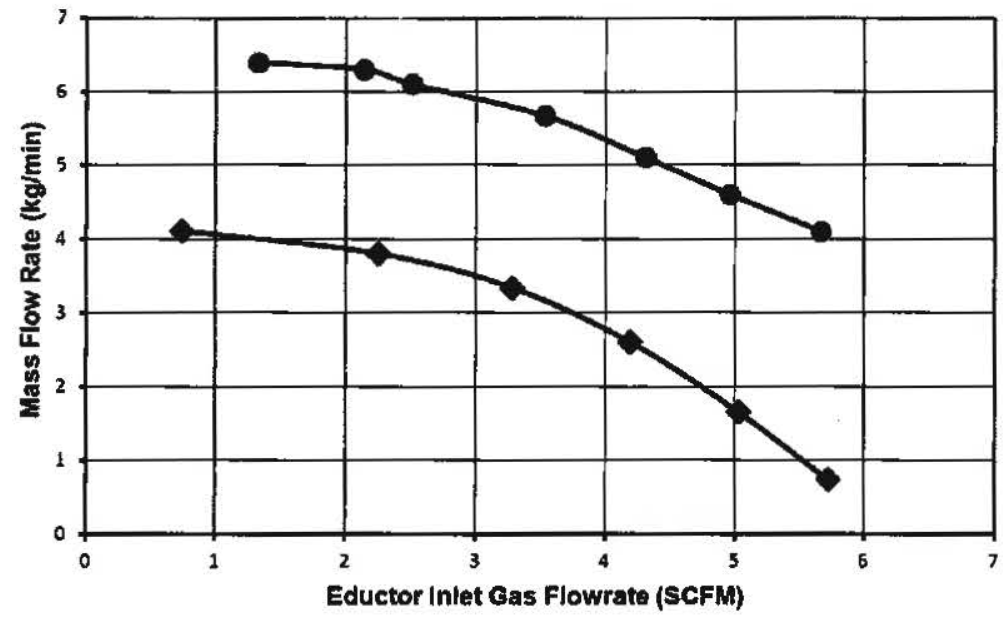

Figure 6. Mass flow rate versus eductor inlet gas flow rate for conveying JSC-1A into ambient environment under 1 -g using compressed dry air as the convey gas. Upper curve (solid circles) is for the supply cylinder fluidized at a pressure of 24.7 psia, while the lower curve (solid diamonds) is for a fluidization pressure of 19.7 psia.

These results indicate that large mass flow rates on the order of several kilograms per minute can be achieved using pneumatic regolith conveying. It would only take a few minutes to deliver a batch size of regolith $(16.5 \mathrm{~kg})$ as a dense dusty gas to an ISRU oxygen production reactor. For a given fluidization pressure in the regolith supply hopper, the data indicates that the regolith mass flow rate actually increases for decreasing values of either the applied gas pressure or the gas flow rate into the eductor. Thus a gas compressor system would only need to consume power for a short period of time to pneumatically transfer a batch of regolith to an ISRU system. We have also found that lunar regolith simulants like JSC-1A, NU-LHT-2M and Tephra can be conveyed pneumatically under reduced gravity conditions. The convey gases that we have used in these reduced gravity flight experiments included both a small molecular mass gas (helium), and a larger one (dry air).

\section{AUGER SYSTEMS FOR CONVEYING PLANETARY REGOLITH}

Auger based regolith feed systems have been shown to work well in ISRU field tests in moving regolith vertically from a receiving hopper on the ground into an ISRU oxygen production reactor at a height of $2.1 \mathrm{~m}$ above ground (Mueller 2010). Augers are simple, easy to control and very robust. Auger feed systems can supply a constant flow of regolith as a function of auger speed/time so that any desired quantity of regolith can be reliably delivered into reactors without requiring regolith mass feedback from the reactors. Some undesirable characteristics of auger feed systems are that they require large heavy motor/gear reductions, and the system does not package as well as some other systems, such as the pneumatic regolith feed system.

Counter-flow auger systems can simultaneously combine regolith transfer with heat recuperation (Zubrin 2009). Tests have shown that it is possible to control and measure the regolith flow and heat transfer very accurately. Results showed that 
counter-flow auger systems could repeatedly transfer more than $50 \%$ of the heat in the hot exit stream to the incoming cool regolith stream. A heat transfer of $62 \%$ was achieved when a counter flowing mixture of solid and gas was tested. It is possible to reduce the heating requirement of a lunar ISRU system by $80 \%$ and reduce the total power consumption by a factor of two by using the counter-flow auger system.

A regolith transfer system was developed at NASA KSC for the ROxygen I field test in 2008, and is shown below in Figure 7. This system used inclined augers with auger motor/gear reductions. A four-sided hopper tapered inward towards the bottom that accepted regolith from an excavator and delivered it to the auger feed inlet. The regolith flowed to the bottom of the hopper where it could be transferred to the hydrogen reduction reactors using augers rotating inside a tube. The regolith fell under gravity into the reactor through isolation valves where the hydrogen reduction reaction occurred.

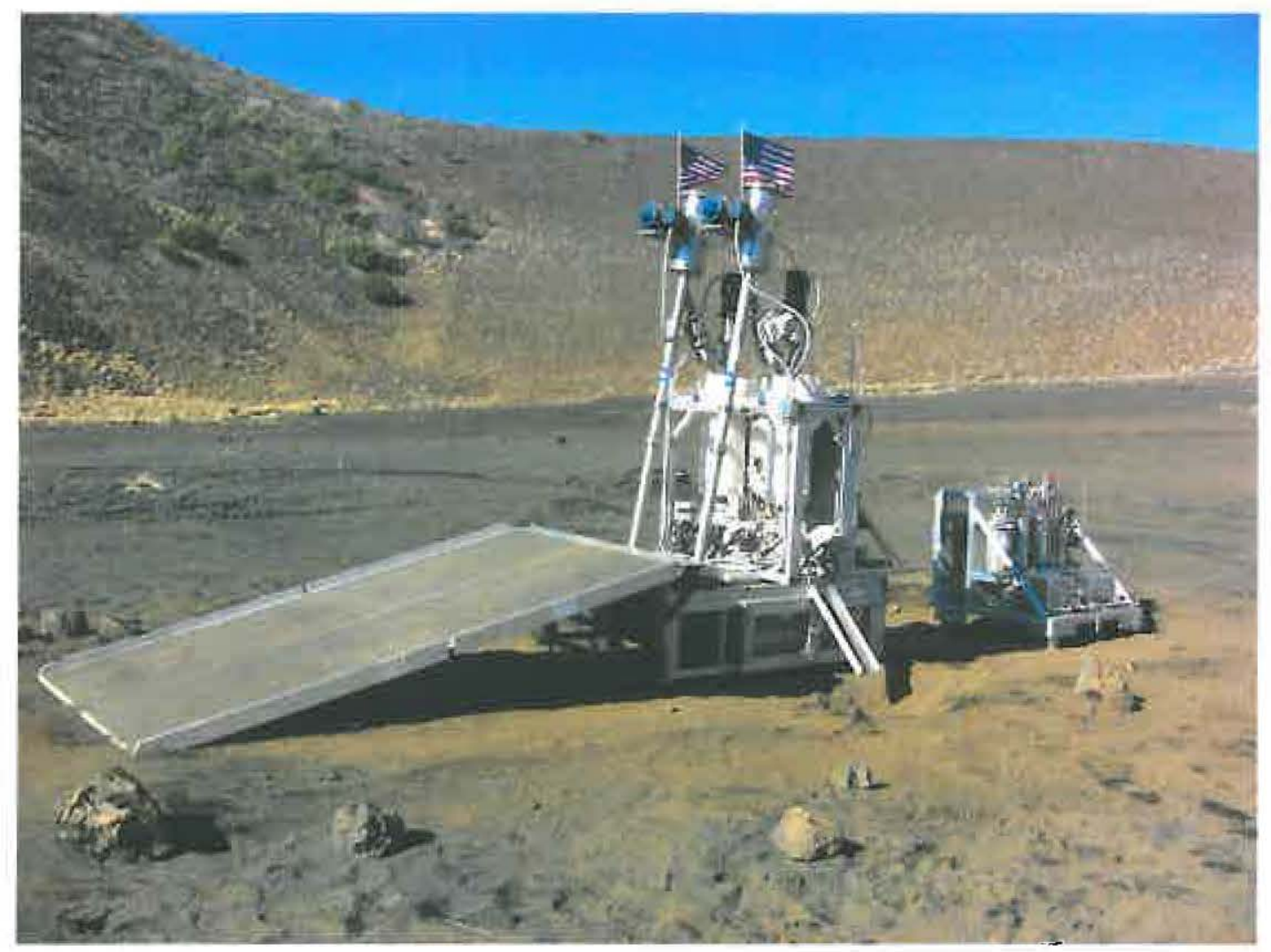

Figure 7. The ROxygen I oxygen production system at the 2008 ISRU field test site in Wahine Valley on Mauna Kea, Hawai'i. The inclined auger regolith transfer system is shown projecting upwards at the top of the ramp to feed Tephra into the reactor.

After completing the chemical processing of the,regolith (Tephra) using hydrogen reduction, the hot regolith $(\sim 1000 \mathrm{C})$ was removed from the system by opening isolation valves (Gemco, Inc.) located at the bottom of the reactor, and allowing the spent material to fall under gravity down a chute to the ground where an excavator 
could later remove the spent material. Figure 8 shows the hot Tephra as it is exits a Gemco valve.

Valves have a critical role in providing a highly reliable and leak tight interface between the harsh near vacuum environment on a planetary surface, and the closed volume of an ISRU system where the temperature and pressure of a gas must be precisely controlled, and the reaction products collected. Also, the valves must be dust tolerant and able to operate effectively over a wide range of temperatures. Field tests of hardware provide important opportunities to check out the performance of integrated systems like ISRU reactors since the environmental conditions faced on planetary surfaces such as the moon will be much more severe than anything that can be experienced during a field test on Earth.

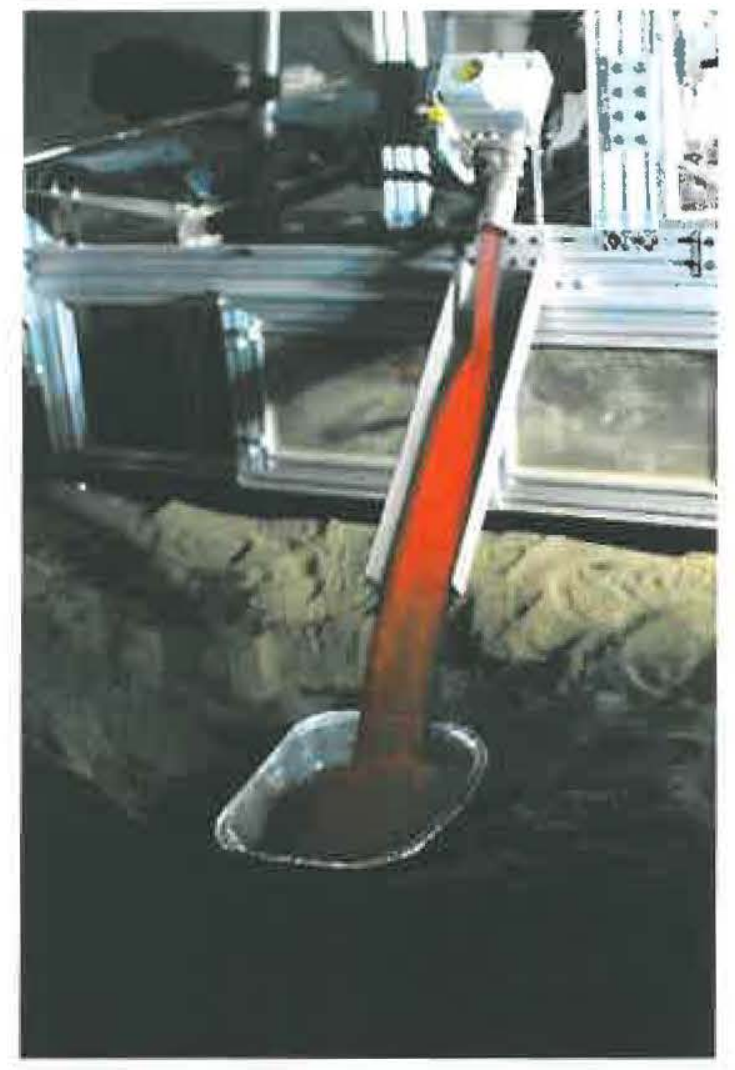

Figure 8. Hot tephra at $\sim 1000 \mathrm{C}$ flowing out of Gemco, Inc valve attached to the bottom of the ROxygen I reactor shown in Fig. 7.

NASA Kennedy Space Center is currently developing a regolith handling system to support an ISRU 2012 field demo (Sanders 2011). For this field test, a trough-type hopper containing an auger will first be positioned on the ground to accept regolith from small to large excavators. The regolith handling system will be able to raise the hopper up to a mockup lander deck where the ISRU system will be located, and then deliver size-sorted regolith into the ISRU system. The regolith handling system will also accept the spent regolith from the ISRU system after processing, and deliver it 
back to the ground where an excavator can remove it. The new regolith handling system for the ISRU field test in 2012 is shown in Figure 9.

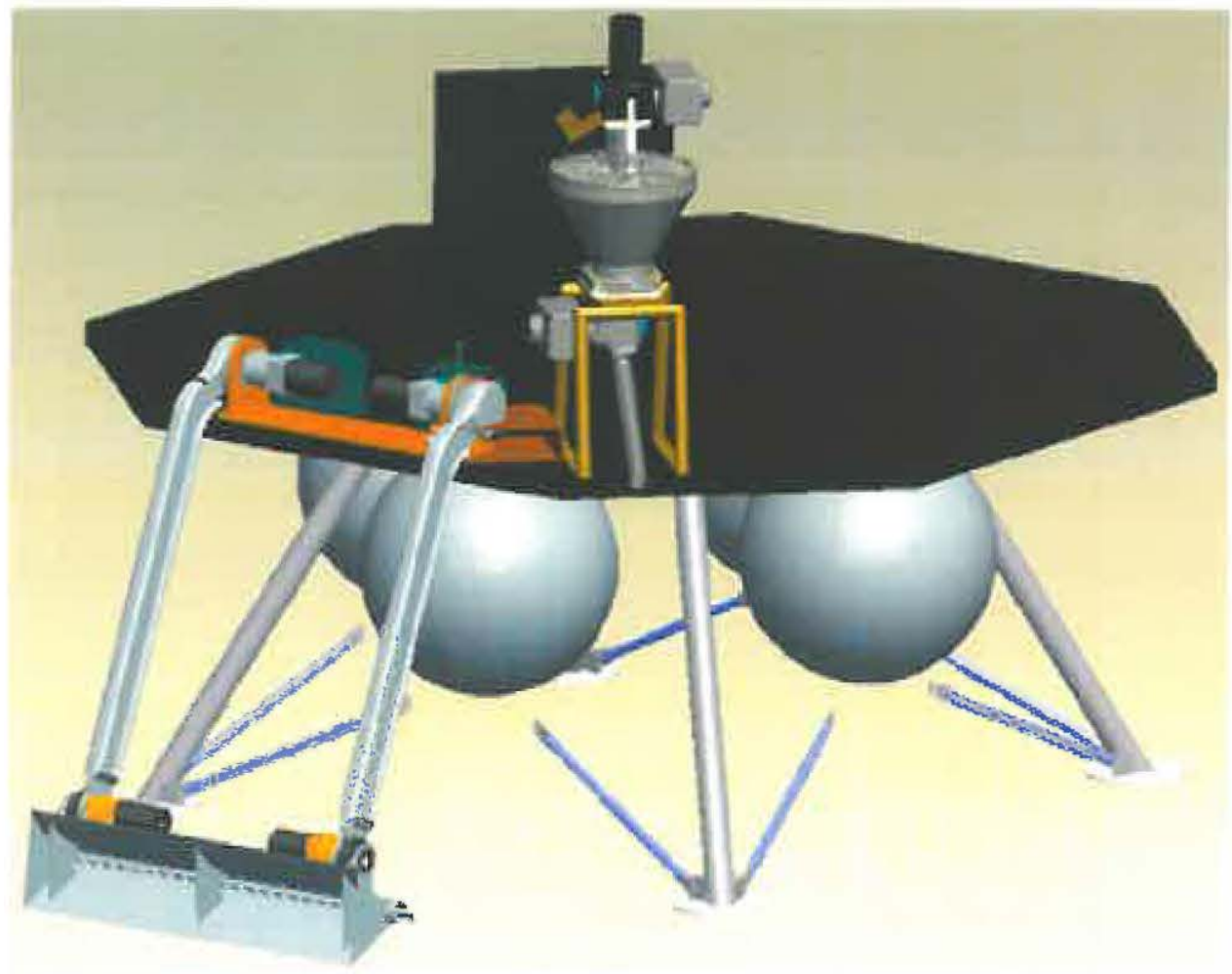

Figure 9. Graphic of the regolith handling system planned for use at an ISRU field test in 2012 to collect regolith from excavators on the ground, and then lift it up to the ISRU regolith processing system located on the lander deck. An auger inside the trough type hopper will deliver size sorted regolith into the ISRU system, and the hopper will later accept spent regolith and deliver it back to the ground.

\section{OTHER METHODS OF CONVEXING PLANETARY REGOLITH}

NASA Kennedy Space Center is charged with developing regolith handling systems for ISRU applications, and has demonstrated techniques such as pneumatic regolith conveying and auger methods at recent ISRU field tests. NASA KSC is also interested in other material handling approaches that could potentially be developed for surface system operations on planetary bodies including low gravity objects like asteroids.

One such technology that is potentially viable for conveying regolith is the spiral elevator, which was developed for various industrial applications on Earth. This device uses a smooth, harmonic, vibratory motion to gently toss material in a forward direction up an inclined spiral ramp without damaging the material. NASA KSC is investigating the use this method to lift regolith from the ground to a desired height where it can be delivered into an ISRU system. 
Carmen Industries, Inc. (Jeffersonville, Indiana) develops commercial equipment for material handling and processing related to conveying bulk media using vibratory conveying equipment, including the spiral elevator. NASA KSC was able to test JSC$1 \mathrm{~A}$ using their commercial spiral elevator system, and obtained positive results. The test fixture shown in Fig. 10 had four 12 inch wide flights with varying rise angles attached to a 20 inch diameter center tube. The unit was driven by two shaker motors that generated harmonic, helical and oscillating motion. The motors are mounted at a 45 degree angle with respect to the center tube axis, and motor speed is controlled using a variable frequency drive to optimize the material delivery rate.

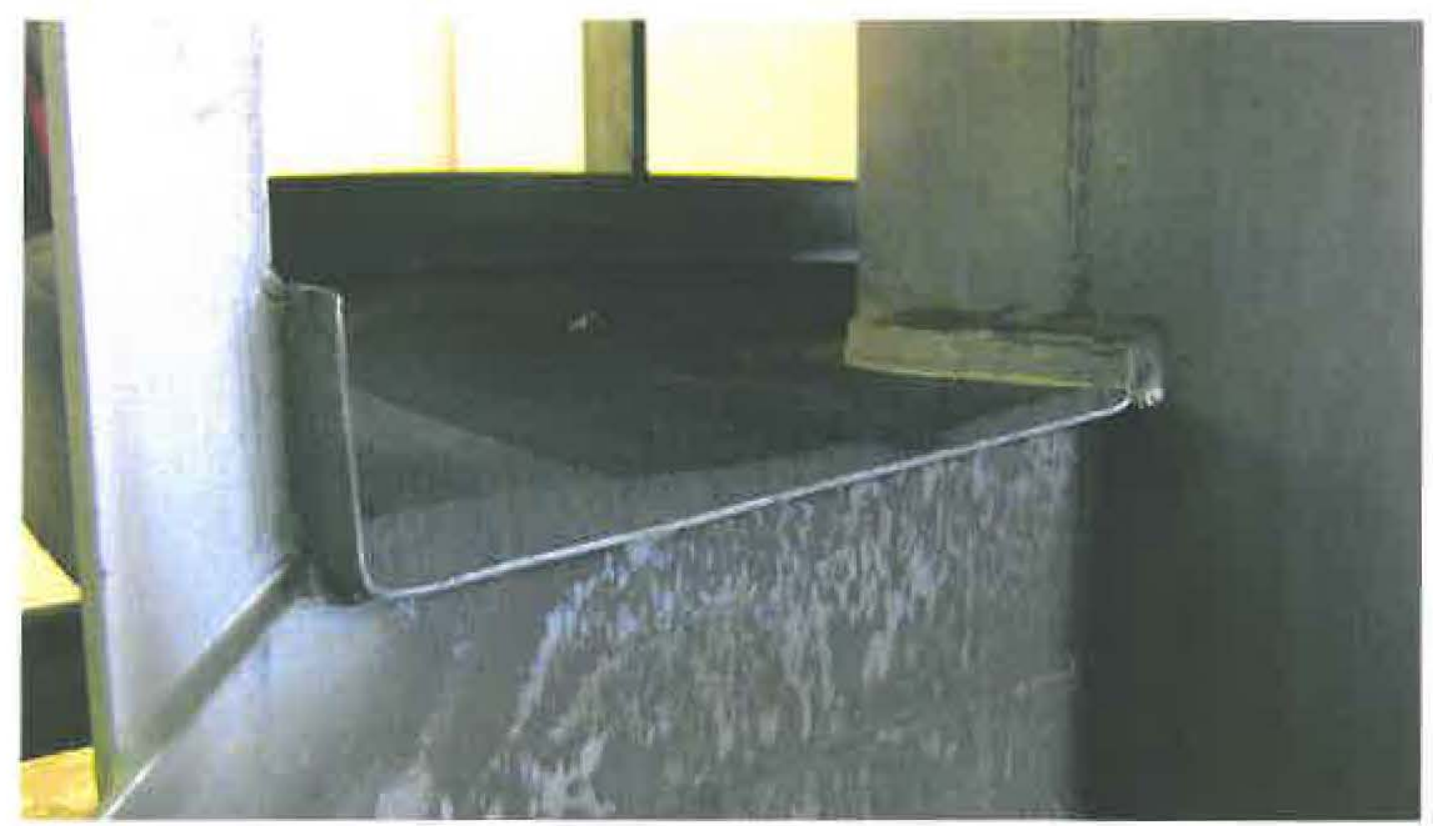

Figure 10. Layer of JSC-1A on spiral elevator test fixture (Carman Industries, Inc.)

The test using the commercial spiral elevator was able to demonstrate that JSC-1A could be conveyed at a very high rate on an unmodified commercially available spiral elevator. The simulant was conveyed with a bed depth that varied from $0.25 \mathrm{inch}$ at the inner diameter to 0.75 inch at the outer diameter. The average linear speed of the layer of JSC 1-A was 3.5 inches/sec, and the commercial system demonstrated an estimated mass delivery rate of $2000 \mathrm{lb} / \mathrm{hr}$. Variation of the flight inclination had little or no effect on the mass delivery rate.

Based on these test results, it appears that spiral elevator technology is feasible for conveying lunar simulant for ISRU applications, and that the spiral elevator is capable of efficiently delivering large quantities of lunar regolith in short period of time. However, commercially available spiral elevator systems are too massive and oversized for the relatively modest demands placed on ISRU regolith feed systems, but they can likely be scaled down in size and mass to become viable regolith delivery systems for various planetary surface system applications. 


\section{CONCLUSIONS}

Current NASA efforts involving ISRU are focused on producing water and oxygen on the Moon and Mars. On the Moon, the lunar regolith contains minerals, such as ilmenite, that chemically react with certain gases when heated to high temperatures. NASA is considering various chemical processes (hydrogen reduction, carbothermal reduction and molten oxide electrolysis) that use reactions with minerals to produce water, from which oxygen can be extracted. Each of these processes needs a regolith handling system to deliver regolith to the reactor chamber, and then remove the spent regolith when the processing is completed. There has been a steady evolution from auger based regolith delivery systems to closed loop pneumatic conveying systems. Depending on the particular ISRU application, each regolith delivery system has its own advantages and disadvantages. In some cases, a combination of auger mechanisms and pneumatic transfer lines may be used, but the pneumatic conveyor system generally allows for better packaging and integration with reactor sub-systems. Although the auger and pneumatic regolith delivery systems have been successful at recent ISRU field tests, other methods of handling and delivering regolith are being investigated to determine their viability on planetary surfaces.

\section{REFERENCES}

Mueller, R.P., Townsend, I.I., Mantovani, J.G., and Metzger, P.T. (2010). "Evolution of Regolith Feed Systems for Lunar ISRU O2 Production Plants," in Proc. 48th AIAA Aerospace Sciences Meeting, Orlando, Florida, January 4-7.

Sanders, G.B. Larson, W.E., Picard, M, and Hamilton, J.C. (2011). "Use of Hawaii Analog Sites for Lunar Science and In-Situ Resource Utilization." Presented at the Second Joint Meeting of the Space Resources Roundtable XII / Planetary \& Terrestrial Mining Sciences Symposium, Ottawa, Canada, June 19-22, 2011.

Zubrin, Robert, Jonscher, Peter, Michael, Sam (2009). "Counterflow Regolith Heat Exchanger Final Report on NASA Contract NNX09CE75P," Pioneer Astronautics, 11111 W. 8th Ave. unit A, Lakewood, CO 80215, July 22, 2009. 